\title{
The Overexpression of Glutamine Synthetase in Transgenic Poplar: A Review
}

\author{
By E. G. Kirby ${ }^{\left.1,{ }^{*}\right)}$, F. Gallardo ${ }^{2)}$, H. MAN $^{1)}$ and R. El-KhatiB ${ }^{1)}$ \\ (Received: September 22, 2006/Accepted: October 30, 2006)
}

\begin{abstract}
In investigating the pivotal role of glutamine synthetase in woody plant development, we have strived to develop an understanding of the biochemical and physiological mechanisms whereby enhanced expression of glutamine synthetase (GS) in poplar contributes to vegetative growth through enhanced nitrogen use efficiency. Considerable effort has also centered on characterization of enhanced resistance of transgenic GS overexpressor lines to abiotic stresses and proposed mechanisms. This summary of our work also focuses on future applications in forest tree improvement.
\end{abstract}

Key words: poplar, nitrogen assimilation, glutamine synthetase, genetic engineering, water stress tolerance, anthranilate synthase.

\section{Nitrogen assimilation in woody plants}

The availability of inorganic nitrogen in soils is often a limiting factor in plant growth and development. Most trees grow in places where nitrate or ammonium ions are the major forms of nitrogen available in soil. There are no differences in the way herbaceous and woody plants acquire inorganic nitrogen from soil. Several reviews of amino acid metabolism and nitrogen metabolism in forest tress have appeared in recent years. Reference should be made to GALLARDO et al. (2003) and MifLIN and HABASH (2003).

Nitrate is the major form of inorganic nitrogen found in the soil (WoLT and WoLT, 1994). Uptake of nitrate and ammonium by plant roots is the result of a balance between the active influx of these ions into root cells and their passive efflux into the soil. Genes encoding components of the inorganic nitrogen transport systems have been identified in different model organisms, including Arabidopsis and Chlamydomonas (GLASS et al., 2002). Identification of their counterparts in trees will require additional research efforts since limited information is currently available regarding nitrogen transport in woody plants. One main difference between herbaceous and woody plants in the manner by which they assimilate nitrogen is that in many tree species the majority of nitrate taken up by the roots is actually reduced in the roots (GALLARDO et al., 2003). Regulation of nitrate uptake in roots depends on several factors including the

\footnotetext{
1) Department of Biological Sciences, Rutgers University, Newark, New Jersey 07102 USA.

2) Departamento de Biología Molecular y Bioquímica, Instituto Andaluz de Biotechnología, Universidad de Málaga, 29071, Málaga, Spain.

*) Corresponding author: EdwARD G. KIRBY, Tel. 973 353-5104, Fax 973 353-5518, E-Mail: ekirby@andromeda.rutgers.edu.
}

concentration of nitrate in soil, the $\mathrm{C}$ and $\mathrm{N}$ status of the plant, the accumulation of amino acids in roots, and active cytokinin levels that up-regulate nitrate uptake at the transcriptional level (GESSLER et al., 2004).

Nitrate is reduced to ammonium by the action of both nitrate reductase $(\mathrm{NR})$ and nitrite reductase $(\mathrm{NiR})$ in root cells and in photosynthetic cells of the leaf. NR and $\mathrm{NiR}$ require cytosolic $\mathrm{NAD}(\mathrm{P}) \mathrm{H}$ and plastidic $\mathrm{NAD}(\mathrm{P}) \mathrm{H}$ (or reduced ferredoxin), respectively, for their reactions.

Ammonium ions produced by NR and NiR are incorporated into the organic pool of molecules in the reaction catalyzed by glutamine synthetase (GS) (EC 6.3.1.2). GS plays a central role in the complex matrix of plant nitrogen metabolism since the enzyme catalyses the incorporation of ammonium into glutamine, an amino acid precursor of glutamate and of all nitrogen compounds required for plant growth.

Plant GS is a holoenzyme composed of eight identical polypeptide subunits and exists as two major isoenzymes, GS1 and GS2, located in different subcellular compartments. The GS isoenzymes display non-overlapping roles (Figure 1). GS1, the cytosolic isoform, is the predominant enzyme in roots and non-photosynthetic tissues. GS1 is less abundant in green tissues. The biological role of GS1 is still not well-defined, but it seems to be involved in the primary assimilation of ammonium from the soil and in recycling of ammonium released through metabolic processes other than photorespiration (i.e. phenylpropanoid biosynthesis; protein and chlorophyll breakdown). Since GS1 in the leaf is expressed specifically in the vascular bundles, a role for GS1 in transport of glutamine to other plant organs has been proposed (CARVAlHo et al., 1992, PEREIRA et al., 1992).

In photosynthetic tissues of most species, plastidic GS2 is responsible for the assimilation of ammonium derived from nitrate reduction and photorespiration (IRELAND and LEA, 1999). GS2 is expressed in angiosperms during plastid differentiation (GALLARDO et al., 1988; GÁlvEZ et al., 1990) and under stress conditions, including water stress (BAUER et al., 1997) or pathogen attack (PÉREz-GARCíA et al., 1998). Genetic and molecular studies have shown that GS may be a key component of plant nitrogen use efficiency and yield (HIREL et al., 2001; OBARA et al., 2001). These reports suggest that cytosolic GS1 plays a central and critical role in nitrogen metabolism and in nitrogen use efficiency in higher plants.

The products of glutamine synthetase, glutamate and glutamine, are precursors of all plant nitrogen compounds (IRELAND and LEA, 1999). GS2 works with plastidic ferredoxin-dependent glutamate synthase (FdGOGAT) (EC 1.4.7.1) in the production of glutamate 


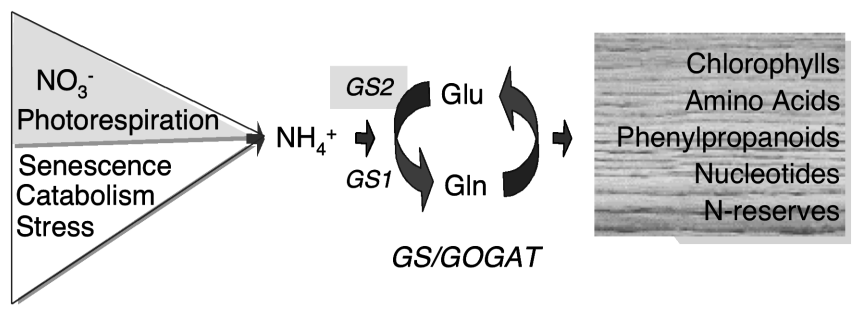

Figure 1. - The GS/GOGAT cycle is the main entry of inorganic $\mathrm{N}$ into the pool of $\mathrm{N}$-compounds in plants. Ammonia produced from nitrate reduction or from the C-2 photorespiratory pathway is assimilated into Gln by plastidic GS (GS2), while cytosolic GS (GS1) is involved in the assimilation of ammonia released from other process. Gln and Glu are the $\mathrm{N}$ donors for the biosynthesis of all plant nitrogen-containing compounds.

from 2-oxoglutarate. GS1 works with plastidic NADHGOGAT (EC 1.4.1.14) to produce glutamate in non-photosynthetic cells, especially in nitrogen fixing nodules in the roots of leguminous species. In the genomes of most plants, GS1 comprises a small gene family of 2-5 members. In contrast, GS2, Fd-GOGAT, and NADH-GOGAT gene families consist of only 1-2 genes (LAM et al., 1996).

Genes encoding GS isoforms and GOGAT appear to be expressed in both angiosperm and gymnosperm species with the exception of GS2. Based on molecular, biochemical, and cytological studies, there is currently no evidence for a plastidic GS2 in conifers (GARCÍA-GUTIÉRREZ et al., 1998). Two GS1 isoenzymes have been reported in pine, GS1a and GS1b, with different patterns of expression and distinct molecular and kinetic properties (ÁvILA et al., 2001; DE LA TORRE et al., 2002). While GS1b exhibits an expression pattern similar to the angiosperm GS1, pine GS1a expression is associated with chloroplast development, suggesting that its physiological role may be similar to that of GS2 in angiosperms.

\section{Biochemical and molecular analysis of GS transgenic lines of poplar}

We have developed a molecular approach to increase glutamine production in transgenic poplar by the overexpression of a conifer glutamine synthetase gene (GALLARDO et al., 1999). A chimeric construct consisting of the cauliflower mosaic virus $35 \mathrm{~S}$ promoter fused to pine cytosolic GS1a cDNA and nopaline synthetase polyadenylation region has been transferred into pBin19 for transformation of hybrid poplar (clone INRA 7171B4, Populus tremula X P. alba) via Agrobacterium tumefaciens (GALLARDO et al., 1999). Transformed poplar lines were selected by their ability to grow on selective medium containing kanamycin.

The presence of the introduced GS sequence in the poplar genome has been verified by Southern blotting and PCR analysis. Transgene expression was detected in all selected poplar lines at the mRNA level. The detection of the corresponding GS polypeptide $(41 \mathrm{kDa})$ and increased GS activity in the transgenics suggest that pine transcripts are correctly processed by the angiosperm translational machinery and that GS1 subunits are assembled into a functional holoenzyme. Fur- thermore, the enzymatic product of the transgene exhibited kinetic and functional properties similar to the pine holoenzyme (Fu et al., 2003).

Biochemical analysis of transgenic poplar lines expressing the pine cytosolic GS has revealed that ectopic expression of the pine GS1a in leaves leads not only to increased GS activity, but also to enhanced levels of chlorophyll and protein (GALLARDO et al., 1999; Fu et al., 2003). As shown in greenhouse studies, transgene expression affected plant features with time resulting in increased protein, increased total GS activity, and increased levels of glutamate synthase (GOGAT) in leaves. However, no differences in either the abundance of the large subunit of Rubisco or total chlorophyll content were detected between transgenics and controls. This suggests that GS1 transgene expression does not alter the differentiation state of leaf (GALLARDO et al., 1999).

Greenhouse studies of GS1 transgenic poplars showed that enhanced GS activity in young leaves was correlated with increases in height growth (Fu et al., 2003). Furthermore, mean net height growth was significantly greater for GS transgenic lines than for non-transformed controls, ranging from a $76 \%$ increase in height at 2 months to $21.3 \%$ increase at 6 months (GALLARDO et al., 1999). In comparison with non-transgenic controls, transgenic trees exhibited significantly greater numbers of leaf nodes and leaves, as well as increases in leaf area. Similar results have been obtained with herbaceous plants (FUENTES et al., 2001; MIFLIN and HABASH, 2002; OLIVEIRA et al., 2002), indicating that modification of cytosolic GS levels may be an appropriate approach for improving growth of crop and forest species.

\section{Field performance of GS transgenic poplars}

Field trials of transgenic trees represent relevant and important assessments of the biological role of introduced genes and are essential to verify the potential use of transgenics for commercial applications. A three-year field study of eight independently-transformed lines of poplar expressing the pine GS1 and non-transgenic control plants was carried out in Andalucía, Spain (JING et al., 2004). Expression of the transgene was stable throughout the period of study. Furthermore, transgenic poplars expressing the pine cytosolic GS exhibited enhanced vegetative growth compared with control plants during the study. Expression of the GS transgene was associated with average heights that were 21,36 and $41 \%$ greater than control plants after the first, second and third year of growth, respectively. These data are in agreement with our growth chamber and greenhouse studies (GALLARDO et al., 1999; Fu et al., 2003). There were no significant differences between transgenic and control field-grown poplars with regard to either total polysaccharide or total lignin contents in trunks throughout the three-year study.

Interestingly, a higher capacity to accumulate bark storage proteins has been observed in the GS-overexpressing poplars grown under field conditions (JING et al., 2004). Vegetative storage proteins (VSPs) in the bark of woody plants serve as sinks for re-absorption of 
nitrogen released from senescing leaves. They also function as a reservoir of reduced nitrogen that can be readily mobilized to support growth during the start of each growing season (WETZEL et al., 2001). Analysis of total proteins from poplar stems revealed accumulation of a $32 \mathrm{kDa}$ VSP concomitantly with stem differentiation (ZHU and COLEMAN, 2001). This polypeptide represented up to $40 \%$ of total protein detected in bark during dormancy. Interestingly, expression of VSP in poplar has been reported to be regulated by glutamine, the main form of nitrogen transported in poplar (SAUTER and VANCLEVE, 1992). The contribution of the cytosolic GS (localized in the vascular bundles) to nitrogen transport from source to sink tissues is clearly important for overall nitrogen economy. Rapid accumulation of the $32 \mathrm{kDa}$ VSP in transgenic poplar could reflect differences in the GS capacities detected in transgenic and control plants and, consequently, a differential availability of organic nitrogen in the form of glutamine for tree growth and development (JING et al., 2004).

\section{GS overexpression results in enhanced nitrogen use efficiency}

In a recent study (MAN et al., 2005) we investigated the hypothesis that enhanced GS expression in poplar results in enhanced efficiency of nitrogen assimilation. Leaves of transgenic poplar showed increases in levels of both free glutamine and total free amino acids compared with leaves of non-transgenic controls. However, levels of free ammonium in leaves of GS transgenic lines were $85 \%$ less $(p<0.01)$ than in leaves of non-transgenic control plants, implying that enhanced levels of GS result in enhanced assimilation of free ammonium into organic nitrogen.

As predicted from earlier work (GALLARDO et al., 1999), when compared with controls grown under both low $(0.3 \mathrm{mM})$ and high $(10 \mathrm{mM})$ nitrate conditions, GS transgenic poplar lines exhibited significant increases in total leaf area, plant height, and leaf dry weight. However, when compared to non-transgenic controls grown under similar nitrogen regimes, the percent increases in growth for transgenic lines were greater under low nitrate availability than under high nitrate availability. Furthermore, ${ }^{15} \mathrm{~N}$-enrichment experiments showed that $27 \%$ more $(\mathrm{p}<0.05)^{15} \mathrm{~N}$ was incorporated into structural compounds in leaves of transgenic lines than in leaves of non-transgenic controls. Taken together, these studies provide strong evidence that genetically engineered lines of poplar displaying ectopic expression of the pine GS1 are characterized by enhanced nitrogen assimilation efficiency .

\section{GS overexpression results in enhanced expression of anthranilate synthase}

We have recently used GS1 transgenic lines of poplar to investigate the effect of glutamine overproduction on the transcriptional regulation of growth. Specifically, we examined the effect of glutamine on expression of anthranilate synthase, a critical enzyme in the production of the plant hormone indole-3-acetic acid (IAA).
Glutamine is directly involved in the initial reaction in the pathway leading to de novo purine biosynthesis (SMITH and ATKINs, 2002). The intermediate products of this pathway, including AMP and GMP, provide purine bases for nucleic acid biosyntheses, as well as for a number of essential coenzymes (NAD, NADP, FAD, and coenzyme A) and for signaling molecules, such as cAMP (SMith and AtKins, 2002). The biosynthesis of IAA is also directly linked with glutamine production (CROzIER et al., 2000; CHO et al., 2000).

The initial step in the pathway for tryptophan-dependent/tryptophan-independent biosynthesis of IAA is the transfer of the $\alpha$-amino group of glutamine to chorismate to produce anthranilate. This reaction is catalyzed by anthranilate synthase (AS). Plant AS holoenzymes characterized to date are tetramers consisting of two $\alpha$ and two $\beta$-subunits encoded by separate nuclear genes. The AS subunits are initially synthesized in the cytosol as precursor proteins with plastid-targeting transit peptides (CRAWFORD, 1989; RADWANSKI and LAST, 1995) and the functional holoenzyme is assembled in the plastids (Poulsen et al., 1993; Bohlmann et al., 1995; Romero and RoBERTS, 1996). The AS $\beta$-subunit is an aminotransferase that cleaves glutamine to produce ammonia, which is then transferred by the $\alpha$-subunit to chorismate producing anthranilate (ZHANG et al., 2001). Nucleotide sequence analyses of AS $\alpha$-subunits from rice, Arabidopsis, Ruta graveolens, and tobacco reveal a high degree of sequence homology (TozAWA et al., 2001; NiYOGI and FinK, 1992; BoHLMANN et al., 1996).

Recent work (MAN and KIRBY, in preparation) has revealed that, compared with leaves of non-transformed control poplar plants, leaves of transgenic poplar expressing the pine cytosolic GS1 showed significant increases in total GS activity, free glutamine, and free tryptophan in leaves. Using RT-PCR, we have shown that the AS $\alpha$-subunit-specific fragments were more strongly amplified in transgenic poplar leaves than in controls. The enhanced free glutamine content in leaves of transgenic poplar leads us to consider the possible role of glutamine in regulating the transcription of AS $\alpha$-subunit gene.

In order to get more direct insight into the role of glutamine on the transcription of AS $\alpha$-subunit, we feed detached tobacco leaves with exogenous glutamine (30 mM). Results showed that feeding with exogenous glutamine boosted transcription of the AS $\alpha$-subunit message by approximately $120 \%$, compared with controls. This adds further evidence that glutamine may directly enhance transcription of the AS $\alpha$-subunit. This increase was a glutamine-specific response.

Little is known about the relationship between glutamine levels and cellular concentrations of IAA (free and conjugated forms). We are currently evaluating levels of free and conjugated IAA in GS transgenic and control poplars. It is possible that the reaction of glutamine and chorismate leading to the production of IAA may represent a central point at which products of nitrogen metabolism (glutamine) and carbon metabolism (chorismate) meet, leading to the regulation of growth and development. 


\section{Phosphinothricin/glufosinate tolerance of poplar GS transgenics}

The mechanism of action of one of most common herbicides used in agriculture, phosphinothricin, or glufosinate (PPT) is through its direct inhibition of glutamine synthetase. PPT is a structural analog of glutamate that irreversibly binds GS resulting in inactivation of the enzyme. Since GS expression is intimately associated with the development of photosynthetic tissues, young leaves are the main target of PPT. The inactivation of GS by PPT results in amino acid depletion leading to inhibition of the C-2 photorespiratory pathway and the inhibition of photosynthesis (LA CUESTA et al., 1992; HoERLEIN, 1994). We have observed enhancement of PPT tolerance in GS overexpressing poplar, both in in vitro studies and in greenhouse experiments (PASCUAL et al., in preparation). The higher viability of transgenic poplar cultivated in presence of PPT was associated higher higher GS content. The responses of both transgenic and control poplar lines to PPT, including increase in GS, Rubisco and $\mathrm{NADP}^{+}$-isocitrate dehydrogenase, seem to depend also on the physiological and developmental state of the photosynthetic tissue.

\section{GS overexpression is correlated with enhanced resistance to water stress}

Although the role of cytosolic GS is not well defined in leaves of angiosperms, its expression in photosynthetic tissues has been associated with responses to biotic and abiotic stresses, fruit ripening, and leaf senescence (BAUER et al., 1997; PÉrez-García et al., 1998; GALLARdo et al. 1988; BRUGIÉRE et al., 2000). Therefore, modification of GS1 levels could have important effects not only on nitrogen partitioning, but also on stress tolerance.

Recent work from our laboratory has examined responses of transgenic poplars overexpressing the pine GS1 gene to untransformed lines prior to, during, and

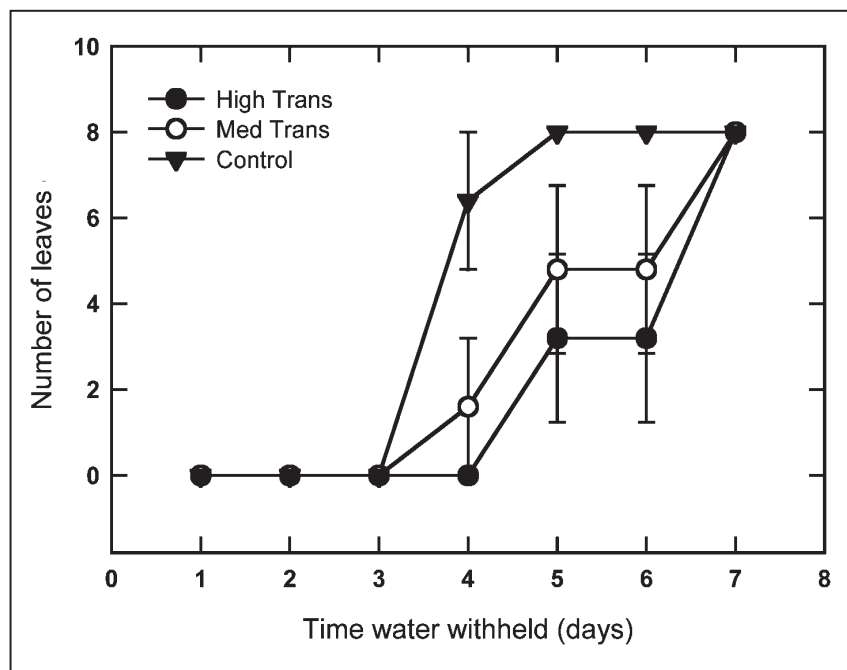

Figure 2. - Leaf dehydration in controls and GS1 transgenic poplar lines. Curve shows values for high and medium performance transgenic lines and non-transgenic controls. The numbers of leaves showing wilting (dehydration) during 7 days of maximum stress were determined. Each value represents the mean of 5 independent measurements; bars indicate one SE. after recovery from transient water stress. When water stress was applied to GS1 transgenic and control poplar lines grown under growth chamber conditions by withholding irrigation for 7 days, transgenic poplars showed fewer dehydrated leaves when compared to non-transgenic control plants $\left[\left(\mathrm{F}_{2,12}=4.94 ; \mathrm{P} \leq 0.05\right)\right.$; type-by-time interaction $\left.\left(\mathrm{F}_{12,72}=2.75 ; \mathrm{P} \leq 0.05\right)\right]$ (Figure 2). This suggests that the GS transgenic poplar lines showed enhanced resistance to drought.

We have investigated possible mechanisms for enhanced water stress resistance in GS transgenic lines in ecophysiological studies (EL-KHATIB et al., 2004). As expected from increased growth of GS transgenic lines, net photosynthetic rates $\left(A_{\text {net }}\right)$ were maintained at higher levels in transgenic poplars than in controls.

Chlorophyll fluorescence data can provide critical insight into mechanisms for stress tolerance. The fundamental principles of chlorophyll fluorescence are straightforward. Light absorbed by chlorophyll molecules can result in one of three events. It can drive photosynthesis (i.e. enhance photochemistry), excess light energy can be dissipated as heat, or energy can be reemitted as light (chlorophyll fluorescence). These three processes compete with each other. Thus, measuring the yield of chlorophyll fluorescence provides critical information on overall photochemistry as well as heat dissipation. Generally, fluorescence yield is highest when photochemistry and heat dissipation are lowest. Changes in chlorophyll fluorescence yield can be used to study the effects of environmental stresses on plants since photosynthesis is often reduced in plants experiencing adverse conditions, such as water deficits, extreme temperatures, nutrient deficiencies, and pathogen attack. Principles of chlorophyll fluorescence and applications of these techniques are reviewed in MAXWELL and JOHNSON (2000).

Fluorescence data showed that energy-dependent quenching of light energy absorbed in the antennae of photosystem II (PSII) is a significant component of the stress response in poplar, especially in GS transgenic lines. This component appears most significant during recovery from water stress. NPQ, a measure of thermaldissipative photoprotection and short-term adjustment to high light levels, is highly dynamic and tightly coupled to xanthophyll cycle kinetics (OsMond, 1994; ANDERSON et al., 1997). PSII antennae transfer efficiency $\left(F_{\mathrm{v}}{ }^{\prime} / F_{\mathrm{m}}{ }^{\prime}\right)$, which is also an energy-dependent parameter and light-adapted PSII yield $\left(\phi_{\mathrm{PSII}}\right)$, both remained higher in the GS1 transgenic poplar lines compared with controls throughout the recovery period. $F_{\mathrm{v}}{ }^{\prime} / F_{\mathrm{m}}{ }^{\prime}$ is an index of the intrinsic efficiency of PSII under ambient light conditions, while $\phi_{\mathrm{PSII}}$ directly reflects PSII efficiency (BARKER and ADAMS, 1997). Therefore, the varying responses of $\mathrm{NPQ}$ and $F_{\mathrm{v}}{ }^{\prime} / F_{\mathrm{m}}{ }^{\prime}$ may reflect differences in fine- and course-scale adjustments in antennae-level thermal dissipation during drought recovery, resulting in PSII yields being maintained at higher levels in GS transgenic poplar lines as compared to controls. Differences in photochemical quenching $(\mathrm{qP})$ between transgenic lines and controls very likely affected $\phi_{\text {PSII }}$ (HYMUS et al., 1999). Higher PSII yield suggests greater poten- 
tial for photochemical processes contributing to electron transport. Taken as a whole, our evidence suggests that overexpression of cytosolic GS in leaves of transgenic poplars under water stress conditions results in engagement of antennae-level, energy-dependent mechanisms that protect the reaction centers during water stress (OSMOND, 1994).

A photoprotective role for photorespiration is controversial. KOZAKI and TAKEBA (1996) showed that transgenic tobacco having twice the normal level of expression of chloroplastic GS also displayed improved photorespiration capacity and increased tolerance to high light intensities. We observed that over-expression of GS in poplar was correlated with a greater post-lower illumination burst of photorespiratory $\mathrm{CO}_{2}$, an indirect assessment of photorespiration (VINES et al., 1983; LEAKEY et al., 2002; LEAKEY et al., 2005). It is likely that photorespiration provides protection against photooxidation in transgenic poplar by providing an alternative pathway for light-induced electron transport, allowing the quantum yield of PSII to be higher in GS1 transgenic lines compared to controls (HosHidA et al., 2000). Greater photorespiratory capacity in GS transgenic poplar could be important in that continued flow of electrons into photorespiration could insure that the transthylakoid $\mathrm{pH}$ gradient is maintained, thereby providing energy for greater antennae-level protection. This may also account for the higher levels of $A_{\text {net }}$ observed in transgenics after recovery from water stress, even under extreme stomatal limitation and is consistent with higher levels of $F_{\mathrm{v}}{ }^{\prime} / F_{\mathrm{m}}$ ' and $\phi_{\mathrm{PSII}}$, which may indicate greater ET capacity in transgenics. During recovery from water stress, when stomatal limitations are high, photorespiration may function as an energy sink in transgenic plants in order to sustain positive levels of Anet.

\section{Conclusions and future work}

To date the work on GS transgenic lines of poplar indicate that overexpression of glutamine synthetase may confer desirable field performance characteristics, including enhanced vegetative growth and stress resistance. Our work has attempted to propose mechanisms whereby enhanced field performance is determined by alterations in glutamine metabolism. Glutamine occupies the central position in the link between carbon and nitrogen metabolism in plants. Furthermore, it is known that specific carbon and nitrogen metabolites can function to regulate the expression of genes involved in critical metabolic processes including photosynthesis, carbon metabolism, nitrogen metabolism, and the allocation of nutrient resources (CORUZZI and ZHOU, 2001; FOYER and Bowsher, 2004; KrAPP et al., 2005). Future work will focus on further elucidation of these mechanisms and of the matrix of interactions of carbon and nitrogen metabolism.

\section{References}

Anderson, J. M., Y. I. PARK and W. S. Chow (1997): Photoinactivation and photoprotection of photosystem II in nature. Physiologia Plantarum 100: 214-233.
Ávila, C., M. F. Suárez, J. Gómez-Maldonado and F. M. CÁNOvas (2001): Spatial and temporal expression of two cytosolic glutamine synthetase genes in Scots pine: functional implications on nitrogen metabolism during early stages of conifer development. The Plant Journal 25: 93-102.

BARKER, D. H. and W. W. ADAMS (1997): The xanthophyll cycle and energy dissipation in differently oriented faces of the cactus Opuntia macrorhiza. Oecologia 109: 353-361.

Bauer, D., K. Biehler, H. Fock, E. Carrayol, B. Hirel, A. MigGe and T.W. Becker (1997): A role for cytosolic glutamine synthetase in the remobilization of leaf nitrogen during water stress in tomato. Physiologia Plantarum 99: 241-248.

Bohlmann, J., T. Lins, W. Martin and U. Eilert (1996): Anthranilate synthase from Ruta graveolens: duplicated AS $\alpha$ genes encode tryptophan-sensitive and tryptophaninsensitive isoenzymes specific to amino acid and alkaloid biosynthesis. Plant Physiology 111: 507-514.

Brugière, N., F. Dubois, C. Masclaux, R. S. Sangwan and B. HiREL (2000): Immunolocalization of glutamine synthetase in senescing tobacco (Nicotiana tabacum L.) leaves suggests that ammonia assimilation is progressively shifted to the mesophyll cytosol. Planta 211: 519-527.

Carvalho, H., S. Pereira, C. Sunkel and R. Salema (1992): Detection of cytosolic glutamine synthetase in leaves of Nicotiana tabacum L. by immunocytochemical methods. Plant Physiology 100: 1591-1594.

Cho, H. J., J. E. Brotherton, H. S. Song and J. M. WiDHOLM (2000): Increasing tryptophan synthesis in a forage legume Astragalus sinicus by expressing the tobacco feedback-insensitive anthranilate synthase (ASA2) gene. Plant Physiology 123: 1069-1076.

Coruzzi, G. and L. ZHOU (2001): Carbon and nitrogen sensing and signaling in plants: emerging "matrix effects". Current Opinion in Plant Biology 4: 247-253.

CRAWFORD, I. P. (1989): Evolution of a biosynthetic pathway: the tryptophan paradigm. Annual Review of Microbiology 43: 567-600.

Crozier, A., Y. Kamiya, G. Bishop and T. Yokota (2000): Biosynthesis of hormones and elicitor molecules, pp. 888-896 in Biochemistry \& Molecular Biology of Plants, edited by B. B. Buchanan, E. GRuissem and R. L. Jones, Courier Companies, Inc., USA.

De la Torre, F., A. García-Gutiérrez, C. Crespillo, F. R. CANTón, C. Avila and F. M. CÁNovas (2002): Functional expression of two pine glutamine synthetase genes in bacteria reveals that they encode cytosolic isoenzymes with different molecular and catalytic properties. Plant and Cell Physiology 43: 802-809.

El-Khatib, R. T., E. Hamerlynck, F. Gallardo and E. G. KIRBY (2004): Transgenic poplar characterized by ectopic expression of a pine cytosolic glutamine synthetase gene exhibits enhanced tolerance to water stress. Tree Physiology 24: 729-736.

FOYER, C. H. and C. BowsheR (2004): Plant carbon-nitrogen interactions from rhizosphere to planet. Journal of Experimental Botany 55: 394.

Fu, J., R. Sampalo, F. Gallardo, F. M. Cánovas and E. G. KIRBY (2003): Assembly of a cytosolic pine glutamine synthetase holoenzyme in leaves of transgenic poplar leads to enhanced vegetative growth in young plants. Plant, Cell and Environment 26: 411-418.

Fuentes, S. I., D. J. Allen, A. Ortiz-Lopez and G. HerNANDEZ (2001): Over-expression of cytosolic glutamine 
synthetase increases photosynthesis and growth at low nitrogen concentrations. Journal of Experimental Botany 52: 1071-1081.

Gallardo, F., J. Fu, Z. P. Jing, E. G. Kirby and F. M. CÁNOVAS (2003): Genetic modification of amino acid metabolism in woody plants, Metabolic Networks in Plants (Special issue). Plant Physiology and Biochemistry 41: 587-594.

Gallardo, F., J. Fu, F. R. CANTON, A. Garcia-Gutierrez, F. M. CÁnovas and E. G. KiRBY (1999): Expression of a conifer glutamine synthetase gene in transgenic poplar. Planta 210: 19-26.

Gallardo, F., S. Gálvez, M. A. Queseda, F. M. Cánovas and I. NÚÑEZ DE CASTRO (1988): Glutamine synthetase activity during the ripening of tomato fruit. Plant Physiology and Biochemistry 26: 747-752.

Gálvez, S., F. Gallardo and F. M. CÁnovas (1990): The occurrence of glutamine synthetase isoenzymes in tomato plants is correlated to plastid differentiation. Journal of Plant Physiology 137: 1-4.

García-Gutiérrez, A., F. Dubois, F. R. Cantón, F. GallarDO, R. S. SANGWAN and F. M. CÁNOvAS (1998): Two different modes of early development and nitrogen assimilation in gymnosperm seedlings. The Plant Journal 13: 187-199.

Gessler, A., S. Kopriva and H. RenNenBerg (2004): Regulation of nitrate uptake at the whole-tree level: interaction between nitrogen compounds, cytokinins and carbon metabolism. Tree Physiology 24: 1313-1321.

GLAss, A. D. M., D. T. BRito, B. N. Kaiser, J. R. KingHORN, H. J. KRONZUCKeR, A. KumaR, M. OKAMOto, S. RAWAT, M.Y. SidDiQI, S. E. UNKLES and J. J. VIDMAR (2002): The regulation of nitrate and ammonium transport systems in plants, Inorganic Nitrogen Assimilation Special issue. Journal of Experimental Botany 53: $855-864$.

Hirel, B., M. Marsolier, A. Hoarau, J. Hoarau, J. Brangeon, R. Schafer and D. P. S. Verma (1992): Forcing expression of a soybean root glutamine synthetase gene in tobacco leaves induces a native gene encoding the cytosolic enzyme. Plant Molecular Biology 20: 207-218.

HoerleIn, G. (1994): Glufosinate (phosphinothricin), a natural amino acid with unexpected herbicidal properties. Review of Environmental Contamination and Toxicology 138: 73-145.

Hoshida, H., Y. TANaKa, T. Hibino, Y. Hayazhi, A. TANaKa, T. TAKABE and T. TAKABE (2000): Enhanced tolerance to salt stress in transgenic rice that overexpresses chloroplast glutamine synthetase. Plant Molecular Biology 43: 103-111.

Hymus, G. J., D. D. Ellsworth, N. R. Baker and S. P. LONG (1999): Does free-air carbon dioxide enrichment affect photochemical energy use by evergreen trees in different seasons? A chlorophyll fluorescence study of mature loblolly pine. Plant Physiology 120: 1183-1191.

IRELAND, R. J. and P. J. LEA (1999) The enzymes of glutamine, glutamate, asparagine, and aspartate metabolism, pp. 49-109 in Plant amino acids: biochemistry and biotechnology edited by B. K. SingH, Marcel Dekker Inc., New York.

Jing, Z. P., F. Gallardo, M. B. Pascual, R. Sampalo, J. Romero, A. Torres De NAVARRA and F. M. CÁNOVAS (2004): Improved growth in a field trial of transgenic hybrid poplar overexpressing glutamine synthetase. New Phytologiost 164: 137-145.
KozaKi, A. and G. TAKeBA (1996): Photorespiration protects C3 plants from photooxidation. Nature 384: $557-560$.

Krapp, A., V. Saliba-Colombani and F. Daniel-Vedele (2005): Analysis of $\mathrm{C}$ and $\mathrm{N}$ metabolisms and of $\mathrm{C} / \mathrm{N}$ interactions using quantitative genetice. Photosynthesis Research 83: 251-263.

la Cuesta, M., A. Muñoz-Rueda, C. González-Murua and M. N. SIVAK (1992): Effect of phosphinothricin (glufosinate) on photosynthesis and chloropyll fluorescence emission by barley leaves illuminated under photorespiratory and non-photorespiratory conditions. Journal of Experimental Botany 43: 246-251.

Lam, H. M., K. T. Coschigano, I. C. Olveira, R. MeloOliveira and G. M. Coruzzi (1996): The molecular genetics of nitrogen assimilation into amino acids in higher plants. Annual Review of Plant Physiology and Plant Molecular Biology 47: 569-593.

Leakey, A. D. B., M. C. Press, J. D. Scholes and J. R. WATLING (2002): Relative enhancement of photosynthesis and growth at elevated $\mathrm{CO}_{2}$ is greater under sunflecks than uniform irradiance in a tropical rain forest seedling. Plant, Cell and Environment 25: 1701-1714.

Leakey, A. D. B., J. D. Scholes and M. C. Press (2005): Physiological and ecological significance of sunflecks for dipterocarp seedlings. Journal of Experimental Botany 56: 469-482.

Man, H. M., R. Boriel, R. El-KhatiB and E. G. Kirby (2005): Characterization of transgenic poplar with ectopic expression of pine cytosolic glutamine synthetase under conditions of varying nitrogen availability. New Phytologist 167: 31-39.

MAXwELL, K. and G. N. JoHnson (2000): Chlorophyll fluorescence- a practical guide. Journal of Experimental Botany 51: 659-668.

MifLin, B. and D. Z. HABASH (2002): The role of glutamine synthetase and glutamate dehydrogenase in nitrogen assimilation and possibilities for improvement in the nitrogen utilization of crops. Journal of Experimental Botany 53: 979-987.

NiYoGi, K. K and G. R. Fink (1992): Two anthranilate synthase genes in Arabidopsis: defense-related regulation of the tryptophan pathway. The Plant Cell 4: 721-733.

OBARA, M., T. SATO and T. YAMAYA (2001): Mapping of QTLs associated with cytosolic glutamine synthetase and NADH-glutamate synthase in rice (Oryza sativa L.) Journal of Experimental Botany 52: 1209-1217.

Oliveira, I. C., T. Brears, T. J. Knight, A. Clark and G. M. CorUzzI (2002): Overexpression of cytosolic glutamine synthetase. Relation to nitrogen, light and photorespiration. Plant Physiology 129: 1170-1180.

Osmond, C. B. (1994): What is photoinhibition? Some insights from comparison of shade and sun plants, pp. 1-24. In: Photoinhibition: Molecular Mechanisms to the Field, edited by N. R. BAKER and J. R. BOYER, Bios Scientific Publishers, Oxford, UK.

Poulsen, C., R. J. M. Bongaerts and R. Verpoorte (1993): Purification and characterization of anthranilate synthase from Catharanthus roseus. European Journal of Biochemistry 212: 431-440.

Pereira, S., H. Carvalho, C. Sunkel and R. Salema (1992): Immunocytolocalization of GS in mesophyll and phloem of leaves of Solanum tuberosum L. Protoplasma 167: 66-73.

Pérez-García, A., S. Pereira, J. Pisarra, A. GarcíaGutiérrez, F. Cazorla, R. Salema, A. DE Vicente and F. M. CÁnovas (1998): Cytosolic localization in tomato 
mesophyll cells of a novel glutamine synthetase induced in response to bacterial infection or phosphinothricin treatment. Planta 206: 426-434.

RaDWANski, E. R, and R. L. LAST (1995): Tryptophan biosynthesis and metabolism: biochemical and molecular genetics. The Plant Cell 7: 921-934.

ROMERo, R. M. and M. F. RoBerTs (1996): Anthranilate synthase from Ailanthus altissima cell suspension cultures. Phytochemistry 41: 395-402.

SAUTER, J. J. and B. VANCLEVE (1994): Storage, mobilization and interrelations of starch, sugars, protein and fat in the ray storage tissue of poplar trees. Trees 8 : 297-304.

Schwanz, P. and A. Polle (2001): Differential stress responses of oxidative systems to drought in pendunculate oak (Quercus robur) and maritime pine (Pinus pinaster) grown under high $\mathrm{CO}_{2}$ concentrations. Journal of Experimental Botany 52: 133-143.

Smith, P. M. C. and C. A. Atkins (2002): Purine biosynthesis. Big in cell division, even bigger in nitrogen assimilation. Plant Physiology 128: 793-802.

Tozawa, Y., H. Hasegawa, T. Terakawa and K. Wakasa (2001): Characterization of rice anthranilate synthase $\alpha$-subunit genes OASA1 and OASA2. Tryptophan accumulation in transgenic rice expressing a feedbackinsensitive mutant of OASA1. Plant Physiology 126: 1493-1506.
Vines, H., M. Senyimba, S. Imbamba and J. Troughton (1983): Environmental responses of the post-lower illumination $\mathrm{CO}_{2}$ burst as related to leaf photorespiration. Plant Physiology 73: 25-30.

Wetzel, S., C. Demmers and J. Greenwood (2001): Seasonally fluctuating bark proteins are a potential form of nitrogen storage in three temperate hardwoods. Planta 178: $275-281$.

Wolt, J. D. and J. WolT (1994): Soil Solution Chemistry: Applications to Environmental Science and Agriculture. John Wiley \& Sons, New York.

Zhang, X., L. Zhang, F. Dong, J. GaO, D. W. Galbraith and C. P. Song (2001): Hydrogen peroxide is involved in abscisic acid-induced stomatal closure in Vicia faba. Plant Physiology 126: 1438-1448.

Zhu, B. and G. Coleman (2001): Phytochrome-mediated photoperiod perception, shoot growth, glutamine, calcium and protein phosphorylation influence the activity of the poplar bark storage protein gene promoter (bspA). Plant Physiology 126: 342-351. 